\title{
Synthesis, Methanolysis, and Asymmetric Polymerization of meta- and para-substituted Triphenylmethyl Methacrylates
}

\author{
Yoshio OKAMOTO, Eiji YashIMA, Motoshi IsHIKURA, \\ and Koichi HATADA \\ Department of Chemistry, Faculty of Engineering Science, \\ Osaka University, Toyonaka, Osaka 560, Japan
}

(Received March 12, 1987)

\begin{abstract}
Five novel meta- and para-substituted triphenylmethyl methacrylates, diphenyl$m$-fluorophenylmethyl methacrylate $\left(m-\mathrm{F}_{1} \operatorname{TrMA}\right), m$-chlorophenyldiphenylmethyl methacrylate ( $m$-Cl ${ }_{1}$ TrMA), tris $\left(m\right.$-chlorophenyl)methyl methacrylate $\left(m-\mathrm{Cl}_{3} \mathrm{TrMA}\right)$, tris $(p$-chlorophenyl)methyl methacrylate ( $\left.p-\mathrm{Cl}_{3} \operatorname{TrMA}\right)$, and tris $\left(m\right.$-tolyl)methyl methacrylate ( $\left.m-\mathrm{Me}_{3} \operatorname{TrMA}\right)$, were synthesized: Their solvolysis rates were measured in $\mathrm{CDCl}_{3}-\mathrm{CD}_{3} \mathrm{OD}(1: 1)$ by ${ }^{1} \mathrm{H}$ NMR spectroscopy at $35^{\circ} \mathrm{C}$. The rates were greatly affected by the substituents. Chlorine and fluorine substituents decreased the rates of the methanolysis and the methyl group accelerated it. These methacrylates were polymerized with chiral anionic initiators, such as $(+)-(2 S, 3 S)$ - or $(-)-(2 R, 3 R)$-dimethoxy-1,4bis(dimethylamino)butane (DDB)- $N, N^{\prime}$-diphenylethylenediamine monolithium amide (DPEDA$\mathrm{Li}$ ) and (-)-sparteine-fluorenyllithium ( $\mathrm{Sp}-\mathrm{FlLi})$ complexes in toluene at $-78^{\circ} \mathrm{C}$. DDB-DPEDA$\mathrm{Li}$ complex was more reactive than the Sp-FlLi complex and gave quantitatively optically active, isotactic polymers with one-handed helicity except for $p-\mathrm{Cl}_{3}$ TrMA. $p-\mathrm{Cl}_{3}$ TrMA did not form a high polymer probably because of the bulkiness of the ester group. The CD spectra of the optically active polymers were different from each other. The copolymerization of $p-\mathrm{Cl}_{3} \operatorname{TrMA}$ with $\operatorname{TrMA}$ by $(+)$ DDB-DPEDA-Li complex gave a low-molecular-weight copolymer of low optical activity which decreased slowly with time probably because of uncoiling of the helix.
\end{abstract}

KEY WORDS Asymmetric Polymerization / Anionic Polymerization /

Triphenylmethyl Methacrylate / Triphenylmethyl Methacrylate Derivatives /

Solvolysis / (-)-Sparteine / 2,3-Dimethoxy-1,4-bis(dimethylamino)butane /

Optically Active Polymer / Helix / Optical Resolution /

Optically active poly(triphenylmethyl methacrylate) [poly(TrMA)] is the first example of optically active vinyl polymer with chirality arising only from the one-handed helical structure of a polymer chain and can be directly prepared by asymmetric polymerization of TrMA with chiral anionic initiators such as (-)-sparteine (Sp)- $n$-butyllithium ( $n$ $\mathrm{BuLi}){ }^{1,2} \mathrm{Sp}$-fluorenyllithium $(\mathrm{Sp}-\mathrm{FlLi}),{ }^{3,4}$ and $(+)-(2 S, 3 S)$ - or (-)-(2R,3R)-dimethoxy1,4-bis(dimethylamino)butane (DDB)lithium amide complexes. ${ }^{5}$ The latter two initiators gave poly(TrMA) having almost pure one-handed helicity. The optically active poly(TrMA) is useful for resolving various racemic compounds $\mathrm{s}^{6,7}$ as a chiral stationary phase for high-performance liquid chromatography (HPLC), particularly when it is adsorbed on macroporous silica gel. ${ }^{8,9}$ The chiral stationary phase can resolve many racemic compounds including hydrocarbons, esters, amides, alcohols, and so on, most of which are difficult to be resolved by other methods. ${ }^{10}$ As eluents, polar solvents like methanol are more effective rather than nonpolar ones like hexane, indicating that the nonpolar interaction between the polymer, probably triphenylmethyl groups, and nonpolar group of enantiomers plays an important role for effective chiral recognition. ${ }^{10}$ However, when methanol 
is used as an eluent, the ester groups of poly(TrMA) are slowly solvolyzed to form methyl triphenylmethyl ether. ${ }^{9}$ In order to lessen this defect and also to study the influence of substituents on optical resolving power, we prepared five novel meta- or parasubstituted triphenylmethyl methacrylates, diphenyl-m-fluorophenylmethyl methacrylate ( $m$ - $\mathrm{F}_{1}$ TrMA), $m$-chlorophenyldiphenylmethyl methacrylate ( $m-\mathrm{Cl}_{1}$ TrMA), tris $(m$-chlorophenyl)methyl methacrylate $\left(m-\mathrm{Cl}_{3} \operatorname{TrMA}\right)$, tris( $p$-chlorophenyl)methyl methacrylate $(p$ $\mathrm{Cl}_{3}$ TrMA), and tris( $m$-tolyl)methyl methacrylate ( $\left.m-\mathrm{Me}_{3} \mathrm{TrMA}\right)$. In this article, we describe the syntheses, methanolyses, and asymmetric polymerization of these triphenylmethyl methacrylate derivatives.
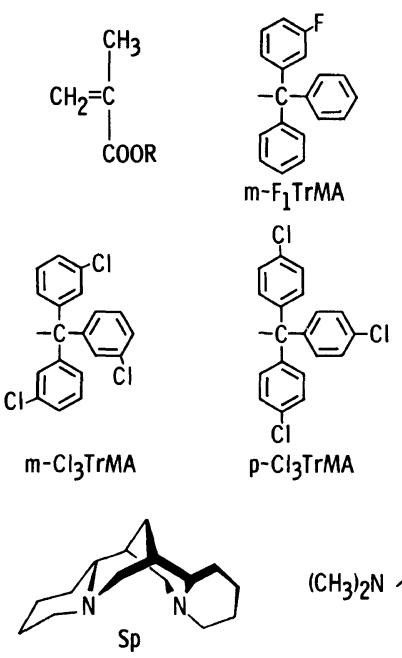

$\mathrm{p}-\mathrm{Cl}_{3} \operatorname{TrMA}$

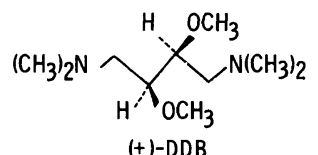

(+)-DDB

\section{EXPERIMENTAL}

\section{Materials}

Syntheses of TrMA Derivatives. The methacrylates were synthesized from silver methacrylate and the corresponding triphenylmethyl chlorides in diethyl ether in a similar manner to the synthesis of $\operatorname{TrMA}^{11}$ and recrystallized from diethyl ether and hexane. The triphenylmethyl chlorides were prepared by the procedure described by Lichtin et al. ${ }^{12}$ with slight modification. As an example, the synthesis of $m-\mathrm{Cl}_{3} \mathrm{TrMA}$ is described. Tris $(m$-chlorophenyl)methanol was prepared by adding methyl $m$-chlorobenzoate to $m$-chlorophenylmagnesium bromide (2.5eq) in dry benzene under dry nitrogen. The reaction mixture was stirred on a steambath for several hours, and quenched with cold saturated aqueous ammonium chloride. The benzene solution was decanted and the residue was washed with ether. The combined extracts were dried over magnesium sulfate. After removal of the solvents, the residue was recrystallized from methanol to give tris( $m$-chlorophenyl)methanol in about $90 \%$ yield. The carbinol was converted to the corresponding chloride with thionyl chloride in dry benzene under dry nitrogen. After the benzene was replaced with diethyl ether, the chloride was allowed to react with silver methacrylate under dark condition. After workup, $m-\mathrm{Cl}_{3} \mathrm{TrMA}$ was purified by recrystallization from diethyl ether and hexane; yield $65 \%$. The characteristics of triphenylmethyl methacrylate derivatives are listed in Table I. Elemental analyses of the methacrylates were in good agreement with their calculated values within error of $0.3 \%$ for carbon, $0.08 \%$ for hydrogen, and $0.15 \%$ for chlorine.

Fluorenyllithium (FlLi) and $N, N^{\prime}$-diphenylethylenediamine monolithium amide (DPEDA-Li) were synthesized from fluorene and $N, N^{\prime}$-diphenylethylenediamine, respectively, with an equivalent amount of $n$-BuLi in toluene. The former salt was soluble in toluene and the latter was scarcely soluble in toluene but became soluble in the presence of a chiral ligand.

(-)-Sparteine (Sigma), (+)- and (-)-DDB (Aldrich) were stirred with calcium hydride overnight and distilled under reduced pressure. Toluene was purified in the usual manner, and distilled under vacuum in the presence of $n$ $\mathrm{BuLi}$ just before use. 
Table I. Characteristics of triphenylmethyl methacrylate derivatives

\begin{tabular}{|c|c|c|c|c|c|c|c|c|c|c|c|}
\hline \multirow{3}{*}{$\begin{array}{l}\text { Monomer } \\
\text { TrMA }\end{array}$} & \multirow{3}{*}{$\frac{\frac{\mathrm{mp}}{{ }^{\circ} \mathrm{C}}}{103.0-103.5}$} & \multirow{2}{*}{\multicolumn{2}{|c|}{$\begin{array}{c}\begin{array}{c}\text { IR (Nujol) } / \\
\mathrm{cm}^{-1}\end{array} \\
\mathrm{C}=\mathrm{O} \quad \mathrm{C}=\mathrm{C}\end{array}$}} & \multicolumn{3}{|c|}{${ }^{1} \mathrm{H} \mathrm{NMR} / \mathrm{ppm}^{\mathrm{a}}$} & \multicolumn{5}{|c|}{${ }^{13} \mathrm{C} \mathrm{NMR} / \mathrm{ppm}^{\mathrm{b}}$} \\
\hline & & & & \multirow{2}{*}{$\frac{\alpha-\mathrm{CH}_{3}}{1.96}$} & \multicolumn{2}{|c|}{$\mathrm{CH}_{2}=$} & \multirow{2}{*}{$\frac{\alpha-\mathrm{CH}_{3}}{18.55}$} & \multirow{2}{*}{$\begin{array}{l}\mathrm{CH}_{2}= \\
125.52\end{array}$} & \multirow{2}{*}{$\begin{array}{c}=\mathrm{C} \\
137.41\end{array}$} & \multirow{2}{*}{$\begin{array}{l}C=O \\
165.12\end{array}$} & \multirow{2}{*}{$\frac{\otimes-C-}{89.91}$} \\
\hline & & 1726 & 1634 & & 5.57 & 6.20 & & & & & \\
\hline$m-\mathrm{F}_{1} \operatorname{TrMA}$ & $85.2-85.6$ & 1720 & 1636 & 1.96 & 5.54 & 6.20 & 18.52 & 125.80 & 137.23 & 165.02 & 89.37 \\
\hline$m-\mathrm{Cl}_{1} \operatorname{TrMA}$ & $78.5-79.5$ & 1726 & 1635 & 1.91 & 5.60 & 6.23 & 18.52 & 125.80 & 137.18 & 165.00 & 89.30 \\
\hline$m-\mathrm{Cl}_{3} \operatorname{TrMA}$ & $123.4-124.0$ & 1727 & 1634 & 1.97 & 5.63 & 6.24 & 18.44 & 126.36 & 136.73 & 164.73 & 88.01 \\
\hline$p-\mathrm{Cl}_{3} \operatorname{TrMA}$ & $140.5-141.5$ & 1722 & 1635 & 1.92 & 5.58 & 6.16 & 18.44 & 126.05 & 136.88 & 164.94 & 88.39 \\
\hline$m-\mathrm{Me}_{3} \operatorname{Tr} \mathrm{MA}$ & $141.0-142.0$ & 1728 & 1636 & 1.97 & 5.58 & 6.22 & 18.61 & 125.29 & 137.58 & 165.12 & 90.03 \\
\hline
\end{tabular}

a In $\mathrm{CCl}_{4}, 35^{\circ} \mathrm{C}$, TMS.

b In $\mathrm{CDCl}_{3}, 27^{\circ} \mathrm{C}$, TMS.

\section{Polymerization Procedure}

Polymerization was carried out in a dry glass ampule under dry nitrogen. A monomer was placed in an ampule, which was then evacuated on a vacuum line and flushed with dry nitrogen. After this procedure was repeated three times, toluene was added with a hypodermic syringe and then cooled to $-78^{\circ} \mathrm{C}$. An initiator solution, which was prepared by mixing FlLi or DPEDA-Li with $1.2 \mathrm{eq}$ of a chiral ligand in toluene at room temperature just before use, was then added to the monomer solution with a syringe. The polymerization was terminated by the addition of a small amount of methanol and the reaction mixture was poured in a large amount of methanol. The polymer was separated by centrifugation and dried as quickly as possible to avoid methanolysis. The polymer was then dissolved in tetrahydrofuran (THF) and added dropwise into a mixture of benzene-hexane $(1: 1, \mathrm{v} / \mathrm{v})$ to separate oligomers as the soluble part.

Polymerization in a $1.0-\mathrm{cm}$ optical cell was carried out in the same manner and the change of optical rotation in the polymerization system at $-78^{\circ} \mathrm{C}$ was directly followed. In order to determine the tacticity and molecular weight, the polymers were converted to poly(methyl methacrylate) (PMMA) by methylation with diazomethane of the poly(methacrylic acid) after hydrolyzed with hydrochloric acid in methanol.

\section{Solvolysis in Methanol}

The solvolysis rates of methacrylates were measured in an NMR sample tube by means of ${ }^{1} \mathrm{H}$ NMR spectroscopy in $\mathrm{CDCl}_{3}-\mathrm{CD}_{3} \mathrm{OD}$ $(1: 1, \mathrm{v} / \mathrm{v})$ at $35^{\circ} \mathrm{C}$. The relative intensities of olefinic protons of a monomer to hydrolyzed methacrylic acid were used for estimating the solvolysis rates.

\section{Measurements}

Optical rotation was measured with a JASCO DIP-181 polarimeter at $25^{\circ} \mathrm{C}$. ${ }^{1} \mathrm{H}$ NMR and ${ }^{13} \mathrm{C}$ MNR spectra were obtained on a JNM-MH-100 (100 MHz) and JEOL FX$100 \quad(25 \mathrm{MHz})$ instruments, respectively. Tetramethylsilane (TMS) was used as the internal standard. Gel permeation chromatographic analysis was accomplished on a JASCO TRI ROTAR-II equipped with UV and polarimetric (JASCO DIP-181C) detectors and a JASCO FLC-A10 equipped with an RI (SHODEX SE-11) detector using THF as the eluent. Two Shodex GPC columns, A80M $(50 \mathrm{~cm} \times 2)$ were connected in series. The molecular weight calibration curves were obtained with polystyrene standards. The molecular weight of poly(triphenylmethyl methacrylate)s was estimated from the GPC curve of the 
PMMA derived from them. Circular dichroism (CD) spectra were measured with a JASCO J40-CD apparatus equipped with a computerized data processor.

\section{RESULTS AND DISCUSSION}

\section{Solvolysis of Monomer by Methanol}

It is well known that triphenylmethyl chloride derivatives react with alcohol to form corresponding ethers and the rates of alcoholysis are affected by the substituents on phenyl groups. ${ }^{13}$ Brown and Okamoto ${ }^{14}$ reported that the rates of solvolysis of substituted triphenylmethyl chlorides decrease by introducing electron-withdrawing groups such as halogens, cyano, and nitro groups, and are accelerated by electron-donating groups like methyl group. Meta substitution was more effective than ortho or para substitution. It has been shown that in the solvolysis of esters of tertiary alcohols, oxygencarbon bonds are cleaved as in the solvolyses of substituted triphenylmethyl chlorides. ${ }^{15}$ These results suggest that meta halogensubstituted triphenylmethyl methacrylates would be more stable against alcoholysis than TrMA, giving optically active polymers with higher durability against methanol than poly(TrMA) as chiral stationary phases for HPLC. We synthesized five meta- or parasubstituted triphenylmethyl methacrylates, and the solvolysis rates were measured in $\mathrm{CDCl}_{3}-\mathrm{CD}_{3} \mathrm{OD}(1: 1, \mathrm{v} / \mathrm{v})$ at $35^{\circ} \mathrm{C}$ by means of ${ }^{1} \mathrm{H}$ NMR spectroscopy. The first-order plots are shown in Figure 1. The values of the rate constants $(k)$ and half-life periods are shown in Table II. The introduction of meta halogen groups greatly decreased the solvolysis rates and the meta methyl group increased it.

In Figure 2 is shown a plot of $\log \left(k / k_{\mathrm{H}}\right)$ for the solvolysis versus Hammett's substituted constant $\left(\sigma^{+}\right)$introduced by Brown and Okamoto in the case of the electrophilic substituent reaction like the solvolysis of the

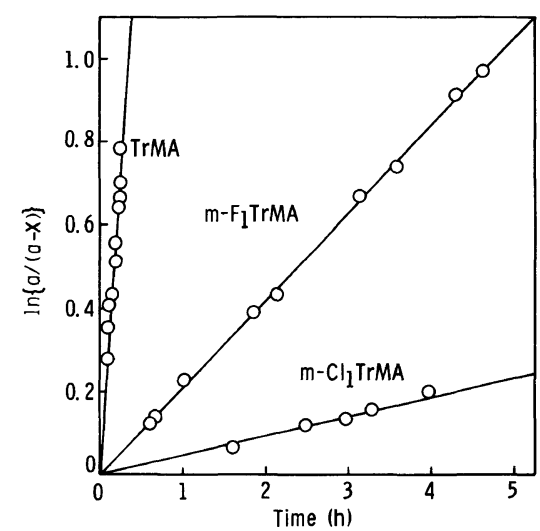

Figure 1. Methanolysis of triphenylmethyl methacrylate derivatives in $\mathrm{CDCl}_{3}-\mathrm{CD}_{3} \mathrm{OD}(1: 1)$ at $35^{\circ} \mathrm{C}$.

Table II. Methanolyșis of methacrylates in $\mathrm{CDCl}_{3}-\mathrm{CD}_{3} \mathrm{OD}(1: 1, \mathrm{v} / \mathrm{v})$ at $35^{\circ} \mathrm{C}^{\mathrm{a}}$

\begin{tabular}{|c|c|c|c|}
\hline \multirow[t]{2}{*}{ Methacrylate } & $k^{\mathrm{b}}$ & $\begin{array}{c}\text { Half-life } \\
\text { period }\end{array}$ & \multirow{2}{*}{$\log k / k_{\mathrm{H}}$} \\
\hline & $h^{-1}$ & $\min$ & \\
\hline$m-\mathrm{Me}_{3} \operatorname{TrMA}$ & 13.0 & 3.2 & 0.66 \\
\hline TrMA & 2.86 & 14.5 & 0 \\
\hline$m-\mathrm{F}_{1} \operatorname{TrMA}$ & 0.21 & 198 & -1.13 \\
\hline$m-\mathrm{Cl}_{1} \mathrm{TrMA}$ & 0.045 & 930 & -1.77 \\
\hline$m-\mathrm{Cl}_{3} \mathrm{TrMA}$ & 0.053 & 786 & -1.73 \\
\hline$p-\mathrm{Cl}_{3} \mathrm{TrMA}$ & 0.056 & 744 & -1.71 \\
\hline
\end{tabular}

a Concentration: $0.39-0.40 \mathrm{~mol} \mathrm{l}^{-1}$.

b Rate constant.

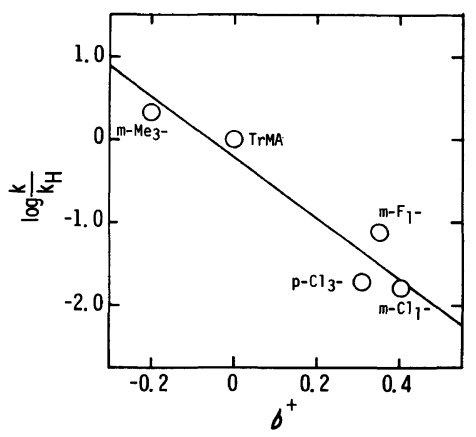

Figure 2. Plots of $\log \left(k / k_{\mathrm{H}}\right)$ versus Hammett's substituted constant $\left(\sigma^{+}\right)$in methanolysis of triphenylmethyl methacrylate derivatives in $\mathrm{CDCl}_{3}-\mathrm{CD}_{3} \mathrm{OD}$ $(1: 1)$ at $35^{\circ} \mathrm{C}$. 
Table III. Asymmetric polymerization of triphenylmethyl methacrylate derivatives in toluene at $-78^{\circ} \mathrm{C}^{\mathrm{a}}$

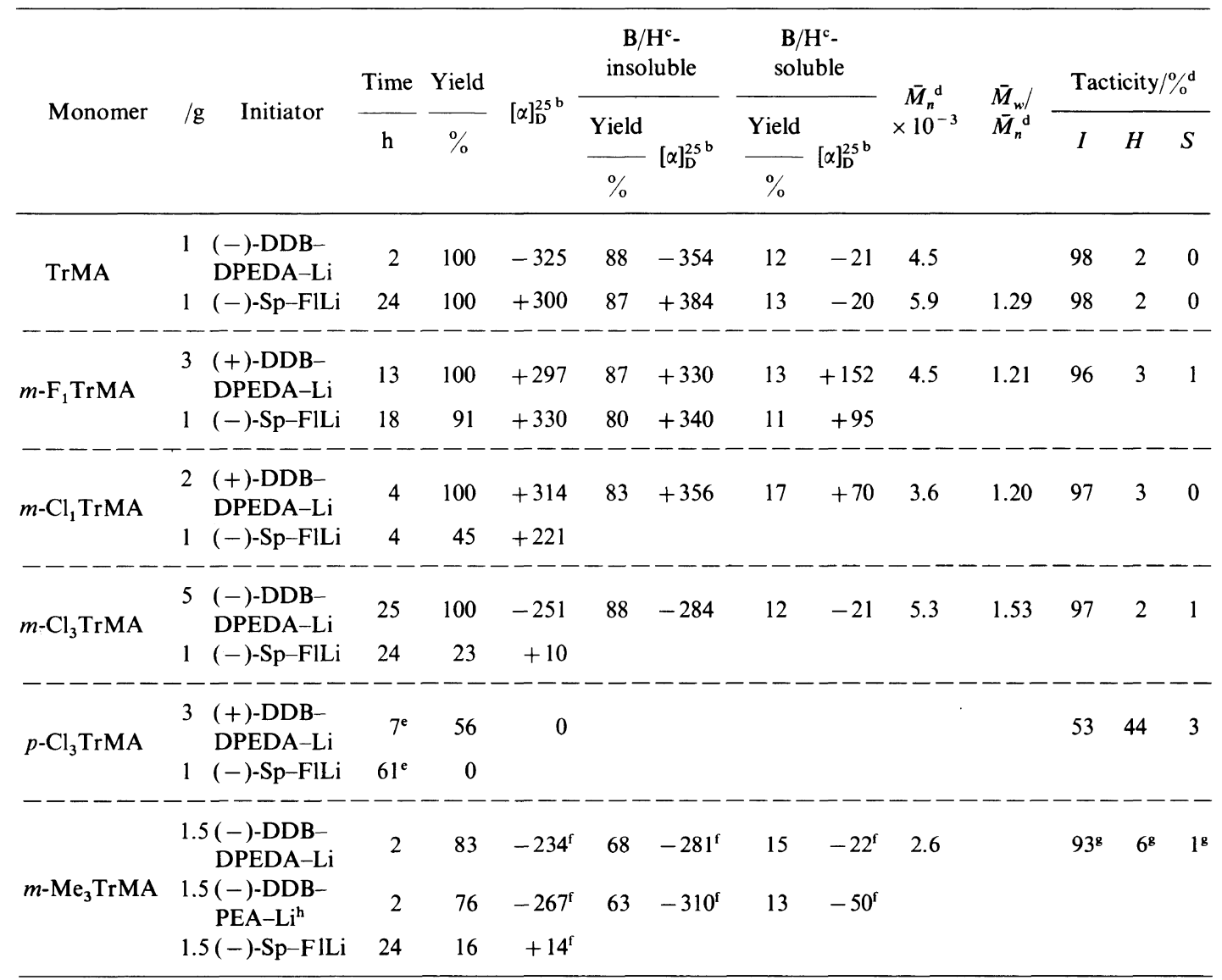

${ }^{\mathrm{a}}[$ Monomer $] /[\mathrm{Li}]=20,[$ Toluene $] /[$ Monomer $]=20(\mathrm{v} / \mathrm{w})$.

b In THF.

c Benzene-hexane $(1: 1)$.

d Estimated from PMMA derived from unfractionated poly(TrMA) derivatives.

e In days.

f At $546 \mathrm{~nm}$ in $\mathrm{CHCl}_{3}$.

g Benzene-hexane $(1: 1)$-insoluble part.

${ }^{\mathrm{h}}$ Lithium amide of ( \pm )- $N$-(1-phenylethyl)aniline.

substituted triphenylmethyl chlorides. ${ }^{14}$ Good relationship was observed. The solvolysis rates may be correlated to the stability of triarylmethyl cations. ${ }^{13}$ Electron-donating substituents seem to accelerate solvolysis by stabilizing the cations.

\section{Asymmetric Polymerization of $\operatorname{Tr} M A$ Deriva- tives}

Table III shows the results of the asym- metric polymerization of six monomers including TrMA using Sp-FlLi and (+)- or (-)DDB-DPEDA-Li complexes as chiral initiators in toluene at $-78^{\circ} \mathrm{C}$. These chiral initiators gave poly(TrMA) of almost $100 \%$ one-handed helicity in the asymmetric polymerization of TrMA. ${ }^{3-5}$ The DDB-DPEDA-Li complex was more reactive than the Sp-FlLi complex and gave quantitatively optically active polymers of high specific rotation in about 


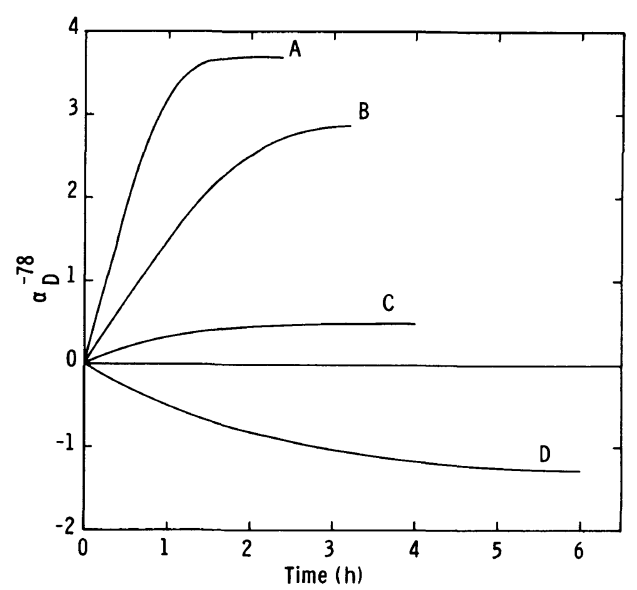

Figure 3. Polymerization of triphenylmethyl methacrylate derivatives with (+)-DDB-DPEDA-Li (A, B, C) and (-)-DDB-DPEDA-Li (D) complexes in a $1.0-\mathrm{cm}$ cell in toluene at $-78^{\circ} \mathrm{C}$. Toluene, $3 \mathrm{ml}$; monomer, $0.15 \mathrm{~g}$; [Monomer] $/[\mathrm{Li}]=20$. Total volume of the reaction mixture was about $2.8 \mathrm{ml}$ at $-78^{\circ} \mathrm{C}$ : A, TrMA; B, $m-\mathrm{Cl}_{1}$ TrMA; $\mathrm{C}, m-\mathrm{Cl}_{3} \operatorname{TrMA} ; \mathrm{D}, m-\mathrm{Me}_{3} \operatorname{TrMA}$.

$24 \mathrm{~h}$ except for $p$ - $\mathrm{Cl}_{3}$ TrMA. $p-\mathrm{Cl}_{3}$ TrMA could not be polymerized to a high-molecular-weight polymer even in a prolonged reaction. Such low reactivity of $p-\mathrm{Cl}_{3} \mathrm{TrMA}$ seems attributable to the steric effect of the para-chlorine atoms because there exist no clear differences in ${ }^{1} \mathrm{H}$ and ${ }^{13} \mathrm{C}$ NMR spectra between $p$ $\mathrm{Cl}_{3}$ TrMA and $m-\mathrm{Cl}_{3}$ TrMA as shown in Table I. The specific rotation of the polymers slightly decreased with an increase in the size and number of substituents. The polymers isolated as methanol-insoluble products always contained $10-20 \%$ oligomers of low optical activity, which were separated by fractionation with benzene-hexane $(1: 1, \mathrm{v} / \mathrm{v})$. The polymers were highly isotactic except for $\operatorname{poly}(p$ $\mathrm{Cl}_{3}$ TrMA) which was a mixture of lowmolecular-weight oligomers. Elemental analyses of halogen-substituted poly(triphenylmethyl methacrylate)s showed that almost no side reaction such as halogen abstracting reaction by lithium complexes took place in the polymerization reaction.

Figure 3 illustrates the change of optical rotation of the polymerization systems that was directly monitored in a $1.0 \mathrm{~cm}$ optical cell

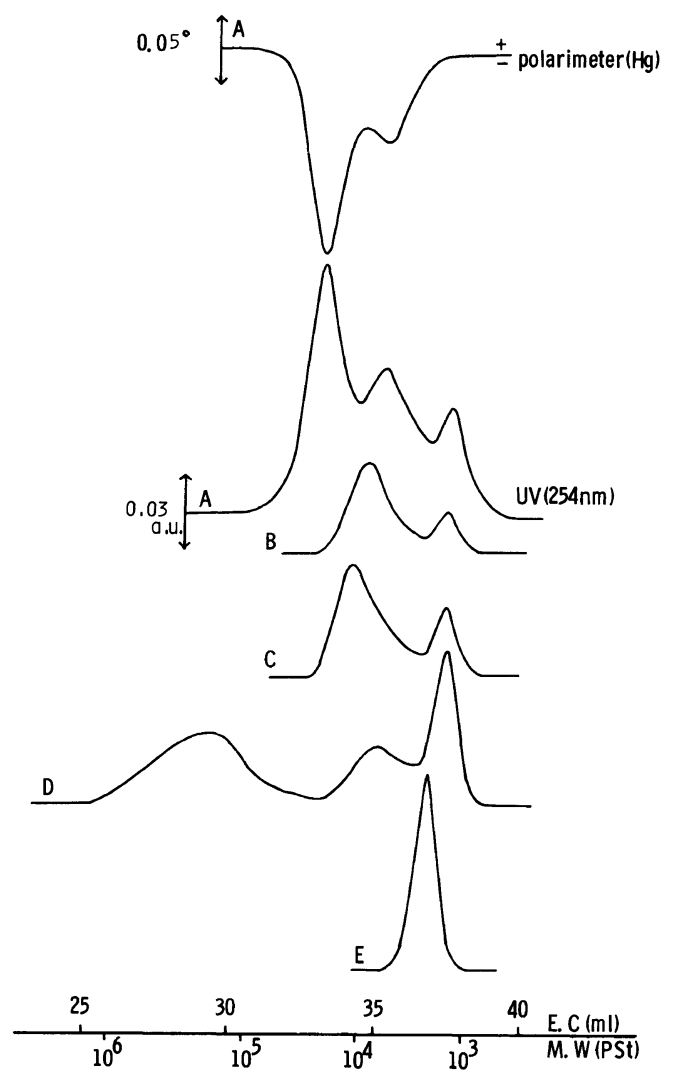

Figure 4. GPC curves of poly(TrMA) derivatives: $A$, TrMA; B, $m-\mathrm{F}_{1} \operatorname{TrMA} ; \mathrm{C}, m-\mathrm{Cl}_{1} \operatorname{TrMA} ; \mathrm{D}, m-\mathrm{Cl}_{3} \operatorname{TrMA}$; $\mathrm{E}, p-\mathrm{Cl}_{3}$ TrMA.

using DDB-DPEDA-Li complex in toluene at $-78^{\circ} \mathrm{C}$. All the systems gave the polymer quantitatively after optical rotation reached a constant value. The final observed rotations of polymers decreased with an increase in number of substituents. The final observed rotation of $\operatorname{poly}\left(m-\mathrm{Cl}_{1} \mathrm{TrMA}\right)$ system in toluene at $-78^{\circ} \mathrm{C}$ was about $40 \%$ smaller than that of poly(TrMA) system although the specific rotation of the both polymers isolated was almost equal. Furthermore, the final optical rotation of poly $\left(m-\mathrm{Cl}_{3} \mathrm{TrMA}\right)$ system was only about $+0.46^{\circ}$ which was about $1 / 8$ and $1 / 5$ of the values of poly(TrMA) and $\operatorname{poly}(m-$ $\mathrm{Cl}_{3}$ TrMA) systems, respectively, and the specific rotation of the living polymer at $-78^{\circ} \mathrm{C}$ was calculated to be $+101^{\circ}$ which was sig- 
nificantly lower than the value $\left([\alpha]_{D}^{25}+250^{\circ}\right)$ after isolation (Table III). This indicates that the specific rotation of poly $\left(m-\mathrm{Cl}_{3} \mathrm{TrMA}\right)$ increased greatly after isolation. The conformation of the polymer formed in the process of polymerization at $-78^{\circ} \mathrm{C}$ may change at higher temperature. Although $m-\mathrm{Me}_{3} \operatorname{TrMA}$ is sterically similar to $m-\mathrm{Cl}_{3} \operatorname{TrMA}$, the final optical rotation of the poly $\left(m-\mathrm{Me}_{3} \mathrm{TrMA}\right)$ at $-78^{\circ} \mathrm{C}$ was much greater than that of poly $(\mathrm{m}$ $\left.\mathrm{Cl}_{3} \operatorname{TrMA}\right)$. Poly $\left(m-\mathrm{Me}_{3} \operatorname{TrMA}\right)$ and $\operatorname{poly}(m-$ $\mathrm{Cl}_{3} \mathrm{TrMA}$ ) may possess different conformations.

Figure 4 shows the GPC curves of the polymers obtained with the DDB-DPEDA-Li complex in toluene at $-78^{\circ} \mathrm{C}$ (unfractionated polymers in Table III). We previously reported that the GPC curve of poly(TrMA) prepared with $\mathrm{Sp}-n$-BuLi complex in toluene at $-78^{\circ} \mathrm{C}$ showed a complicated distribution containing a low-molecular-weight component of low optical activity. ${ }^{2}$ The GPC curve of poly(TrMA) obtained with (-)-DDB-DPEDA - $\mathrm{Li}$ also demonstrated a similar complicated distribution pattern (Figure 4(A)). Although two higher-molecular-weight components showed high optical activity, the oligomer of molecular weight less than 2000 was almost optically inactive. The oligomer could be excluded as a soluble part by fractionation with benzene-hexane $(1: 1, \mathrm{v} / \mathrm{v})$. Other polymers except $\operatorname{poly}\left(p-\mathrm{Cl}_{3} \mathrm{TrMA}\right)$ also contained oligomers of low optical activity and showed complicated GPC curves. $\operatorname{Poly}\left(p-\mathrm{Cl}_{3} \operatorname{TrMA}\right)$ exhibited almost no optical activity and a simple GPC peak with a narrow distribution at low-molecular-weight region. $p$ - $\mathrm{Cl}_{3} \mathrm{TrMA}$ might be difficult to polymerize beyond a certain degree of polymerization due to the sterical reason.

The CD spectra of the optically active polymers (benzene-hexane-insoluble part in Table III) were measured (Figure 5). The bands at $250-280 \mathrm{~nm}$ assigned to the absorption of phenyl groups showed different spectral patterns. The absorption around $240 \mathrm{~nm}$,

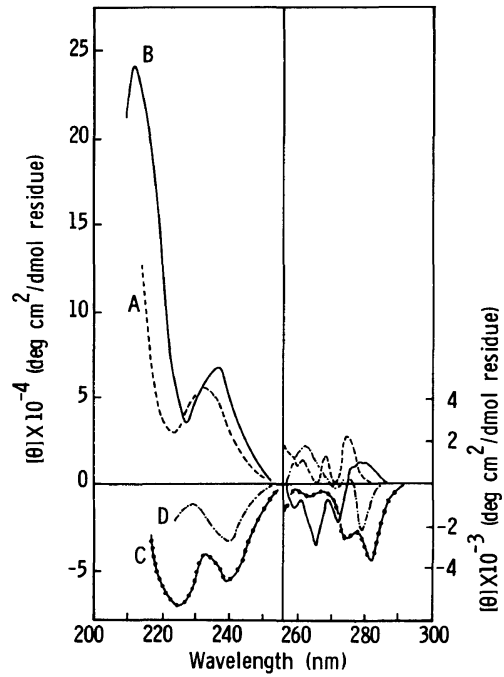

Figure 5. CD spectra of poly $\left(m-\mathrm{F}_{1} \operatorname{TrMA}\right)$ (A), $\operatorname{poly}\left(m-\mathrm{Cl}_{1} \mathrm{TrMA}\right)$ (B), poly $\left(m-\mathrm{Cl}_{3} \mathrm{TrMA}\right)$ (C), and poly $\left(m-\mathrm{Me}_{3} \mathrm{TrMA}\right)$ (D) in THF. The benzene-hexane $(1: 1)$-insoluble parts in Table III were used as samples.

which may be due to carbonyl groups, shifted to higher wavelength as the size and number of substituents increased. Previously, we proposed that triphenylmethyl groups in optically active poly(TrMA) likely take either a right- or left-handed propeller structure accompanying the formation of the one-handed helical structure of a polymer chain and such a chiral propeller structure may play an important role for chiral recognition in optical resolution. ${ }^{16}$ The differences in CD spectra of these polymers may be attributed to the different propeller structures or conformation of ester groups including carbonyl groups. These differences led to different chiral recognition ability of the polymers in the optical resolution of racemic compounds when used as chiral stationary phase for HPLC, and the results will be reported separately.

\section{Asymmetric Copolymerization}

Table IV shows the results of the asymmetric copolymerization of $\operatorname{TrMA}\left(\mathrm{M}_{1}\right)$ with $m-\mathrm{Cl}_{3^{-}}, p-\mathrm{Cl}_{3^{-}}$, and $m-\mathrm{Me}_{3} \operatorname{TrMA}\left(\mathrm{M}_{2}\right)$ by $(+)-$ DDB-DPEDA-Li complex in toluene at 
Table IV. Asymmetric copolymerization of TrMA

$\left(\mathrm{M}_{1}\right)$ with $\mathrm{M}_{2}$ by (+)-DDB-DPEDA-Li complex in toluene at $-78^{\circ} \mathrm{C}^{\mathrm{a}}$

\begin{tabular}{|c|c|c|c|c|}
\hline $\mathbf{M}_{2}$ & $\frac{\mathrm{M}_{1}}{\mathrm{M}_{2}}$ & $\frac{\text { Time }}{\mathrm{h}}$ & $\frac{\text { Yield }}{\%}$ & {$[\alpha]_{\mathrm{D}}^{25 \mathrm{~b}}$} \\
\hline$m-\mathrm{Cl}_{3} \mathrm{TrMA}$ & $\begin{array}{l}2 \\
1 \\
0.5\end{array}$ & $\begin{array}{l}22 \\
22 \\
22\end{array}$ & $\begin{array}{l}100 \\
100 \\
100\end{array}$ & $\begin{array}{l}+276 \\
+275 \\
+255\end{array}$ \\
\hline$p-\mathrm{Cl}_{3} \mathrm{TrMA}$ & $\begin{array}{l}1 \\
1 \\
1^{\mathrm{f}}\end{array}$ & $\begin{array}{c}4 \\
25^{\mathrm{c}} \\
73\end{array}$ & $\begin{array}{l}52 \\
90 \\
93\end{array}$ & $\begin{array}{l}+11 \\
+70^{\mathrm{d}}(+22)^{\mathrm{e}} \\
+187^{\mathrm{d}}(+151)^{\mathrm{e}}\end{array}$ \\
\hline$m-\mathrm{Me}_{3} \operatorname{Tr} \mathrm{MA}^{\mathrm{g}}$ & 1 & 24 & 100 & $-263^{\mathrm{h}}$ \\
\hline
\end{tabular}

a $\left[\mathrm{M}_{1}+\mathrm{M}_{2}\right] /[\mathrm{Li}]=20$.

b In THF.

c In days.

d At $365 \mathrm{~nm},[\alpha]_{365}^{25} /[\alpha]_{\mathrm{D}}^{25} \simeq 4$.

e Specific rotation after $4 \mathrm{~h}$ is shown in parenthesis.

f At $-40^{\circ} \mathrm{C}$.

g (-)-DDB was used.

${ }^{\text {h }}$ Rotation $\left([\alpha]_{\mathrm{D}}^{25}\right)$ of benzene-hexane $(1: 1)$-insoluble $(87 \%)$ and -soluble parts $(13 \%)$ was $-289^{\circ}$ and $-97^{\circ}$, respectively.

$-78^{\circ} \mathrm{C}$. The specific rotation of poly(TrMAco- $\left.m-\mathrm{Cl}_{3} \mathrm{TrMA}\right) \mathrm{s}$ was almost the same as that of poly $\left(m-\mathrm{Cl}_{3} \mathrm{TrMA}\right)$, regardless of the molar ratio $\left(\mathbf{M}_{1} / \mathbf{M}_{2}\right)$ within the experimental conditions, and the CD spectra of all the copolymers were very similar to that of $\operatorname{poly}(\mathrm{m}$ $\mathrm{Cl}_{3}$ TrMA). A similar result was also obtained in the copolymerization of $m-\mathrm{Me}_{3} \mathrm{TrMA}$ with TrMA. Although $p-\mathrm{Cl}_{3} \mathrm{TrMA}$ could not be polymerized to a high-molecular-weight polymer, copolymerization with TrMA gave the low-molecular-weight copolymer of low optical activity, which decreased slowly with time probably because of uncoiling of the helix.

\section{CONCLUSIONS}

Five meta- and para-substituted triphenylmethyl methacrylates were synthesized. The rates of methanolyses greatly decreased by the introduction of meta-halogen groups and in- creased by methyl group. Therefore, the methacrylates with electron-withdrawing substituents are preferable to obtain more durable chiral stationary phases for HPLC. All methacrylates except for $p$ - $\mathrm{Cl}_{3} \mathrm{TrMA}$ gave optically active one-handed helical polymers with chiral lithium initiators in toluene at $-78^{\circ} \mathrm{C} . p$ $\mathrm{Cl}_{3}$ TrMA could not be polymerized to a highmolecular-weight polymer. The CD spectra of the optically active polymers were greatly different from each other. The differences of CD spectra may be attributed to the different propeller structures and/or conformations of the ester groups.

\section{REFERENCES}

1. Y. Okamoto, K. Suzuki, K. Ohta, K. Hatada, and H. Yuki, J. Am. Chem. Soc., 101, 4769 (1979).

2. Y. Okamoto, K. Suzuki, and H. Yuki, J. Polym. Sci., Polym. Chem. Ed., 18, 3043 (1980).

3. Y. Okamoto, T. Takeda, and K. Hatada, Chem. Lett., 757 (1984).

4. Y. Okamoto, E. Yashima, T. Nakano, and K. Hatada, Chen. Lett., 759 (1987).

5. Y. Okamoto, H. Shohi, and H. Yuki, J. Polym. Sci., Polym. Lett. Ed., 21, 601 (1983).

6. H. Yuki, Y. Okamoto, I. Okamoto, J. Am. Chem. Soc., 102, 6356 (1980).

7. Y. Okamoto, I. Okamoto, and H. Yuki, Chem. Lett., 835 (1981).

8. Y. Okamoto, S. Honda, I. Okamoto, H. Yuki, S. Murata, R. Noyori, and H. Takaya, J. Am. Chem. Soc., 103, 6971 (1981).

9. Y. Okamoto, S. Honda, K. Hatada, and H. Yuki, J. Chromatogr., 350, 127 (1985).

10. Y. Okamoto and K. Hatada, J. Liquid Chromatogr., 9, 369 (1986) and references sited therein.

11. N. A. Adrova and L. K. Prokhorova, Vysokomol. Soedin., Ser. A., 3, 1509 (1961).

12. N. N. Lichtin and M. J. Vigmale, J. Am. Chem. Soc., 79, 579 (1957).

13. A. C. Nixon and G. E. Brace, J. Am. Chem. Soc., 58, 492 (1936).

14. H. C. Brown and Y. Okamoto, J. Am. Chem. Soc., 80, 4979 (1958).

15. B. K. Morse and D. S. Tarbell, J. Am. Chem. Soc., 74, 416 (1952).

16. Y. Okamoto, S. Honda, E. Yashima, and H. Yuki, Chem. Lett., 1221 (1981). 